\title{
El esperanto en los medios periodísticos: una aproximación a la historia esperantista de España
}

\author{
Esperanto in media: an approach to the esperantist history of Spain
}

\author{
Patricia Merello Guzmán, Universidad de Sevilla \\ pamegu2010.11@gmail.com | https://orcid.org/0000-0002-6602-9274 \\ C/Diego Niño $111^{\circ} \mathrm{B}$ El Puerto de Santa María C.P 11500 Cádiz
}

\begin{abstract}
Resumen
El presente estudio aborda la repercusión del movimiento esperantista en los medios de comunicación en España, tanto en la prensa de la época como en las publicaciones editadas en esperanto por las diversas asociaciones. Se trata de un recorrido que comienza en 1898, desde la aparición de la primera crónica periodística a favor del esperanto realizada por $\mathrm{Pi}$ y Margall en EI Nuevo Régimen, hasta el término de la Guerra civil en 1939. De esta forma, se detalla la llegada de la propuesta lingüística del polaco L.L Zamenhof al territorio español atendiendo a la emergencia de asociaciones que se ocuparon de la divulgación del idioma a través de sus publicaciones en cada periodo.

El desarrollo del esperantismo acogerá el primer congreso universal en España durante el reinado de Alfonso XIII. Tras el duro golpe que supuso la Gran Guerra, de 1923 a 1931 tuvo lugar la dictadura de Primo de Rivera que dejó atrás un periodo dorado del movimiento obrero. Con la llegada de la Segunda República en 1931 tuvo lugar una etapa de florecimiento donde republicanos, masones, católicos y militares, impulsaron la propagación del idioma. Hasta entonces, España estuvo dividida en grupos neutrales y obreros, que a su vez estuvieron fragmentados en anarquistas, socialistas o comunistas. Del mismo modo, se creó un movimiento catalán muy activo y presente que cesaría con el triunfo del bando franquista en la Guerra civil. El estudio profundiza en publicaciones esperantistas que conforman una realidad escasamente atendida en el mundo académico.
\end{abstract}

\begin{abstract}
The present study deals with the repercussion of the esperanto movement in the media in Spain, both in the press of the time and in publications published in esperanto by the various associations. It is a journey that begins in 1898, from the appearance of the first journalistic chronicle in favor
\end{abstract}


of esperanto written by Pi y Margall in El Nuevo Régimen, until the end of the Civil War in 1939. In this way, the arrival of the linguistic proposal of the Polish L.L Zamenhof to Spanish territory is detailed, taking into account the emergence of associations that dealt with the dissemination of the language through their publications in each period.

The development of Esperantism will host the first universal congress in Spain during the reign of Alfonso XIII. After the hard blow that the Great War supposed, from 1923 to 1931, the dictatorship of Primo de Rivera took place, leaving behind a golden period of the labor movement. With the arrival of the Second Republic in 1931, a flourishing stage took place where Republicans, Freemasons, Catholics and the military promoted the spread of the language. Until then, Spain was divided into neutral groups and workers, which in turn were fragmented into anarchists, socialists or communists. In the same way, a very active and present Catalan movement was created that would end with the triumph of the Francoist side in the civil war. The study delves into esperanto publications that make up a reality poorly attended in the academic world.

Palabras clave: prensa esperantista, cabeceras de la época, movimiento obrero, cursos de esperanto, congresos universales.

Keywords: esperantist press, headers of the time, labor movement, esperanto courses, universal congresses.

\section{INTRODUCCIÓN Y REVISIÓN TEÓRICA}

«En ese entonces se hablaba un solo idioma en toda la tierra». Sin embargo, la decisión de construir una torre para alcanzar las puertas del cielo condenó a la humanidad con la incomprensión. Según las escrituras bíblicas, Dios castigó al mundo con la diversidad lingüística: "Será mejor que bajemos a confundir su idioma, para que ya no se entiendan entre ellos mismos". La desobediencia de Babel preocupó a Ludovico Lázaro Zamenhof quien a finales del siglo XIX creía firmemente que la imposición de barreras idiomáticas fue la causa de los enfrentamientos que imposibilitaban la convivencia pacífica. El joven polaco se rebeló contra la incomunicación y en 1887 dio a conocer un proyecto de lengua universal, el esperanto, que se expandiría por todos los rincones del planeta.

Antes de que Blas Infante, J.R.R Tolkien o Miguel de Unamuno aprendieran esperanto, muchos pensadores ya se percataron de la necesidad de crear una lengua común. En 1532 el humanista Juan Luis Vives afirmaba en su obra De Disciplinis: "Sería una gran ventaja para la humanidad que existiera una sola lengua, que todos los pueblos puedan aplicar». Un siglo más tarde Miguel de Cervantes aludía en El ingenioso hidalgo don Quijote de la Mancha a una lengua «ni castellana, ni de otra nación alguna, sino una mezcla de todas las lenguas, con la cual todos nos entendemos».

El presentado afán por lograr el entendimiento se materializó en multitud de propuestas de idiomas fallidos. «Es evidente que no existe una lengua nacional que reúna las cualidades que se requieren para desempeñar el trascendental papel de lengua universal» (Nájera, 2014, p.80) De este modo, el esfuerzo dio lugar a diversos ejemplos como la Lingua ignota o la pasigrafía de Leibniz en el 
siglo XII. Pero fue durante el siglo XIX cuando florecieron los intentos. En Francia, Jean Sudre constituyó en 1827 un idioma musical al que llamó el Soresol. En 1845 aparece el primer proyecto en España de la mano del científico Sotos Ochando que llegó a fundar una asociación con un boletín. La Cosmoglossa de Rudelle en 1858 o el tupal del valenciano Juan Ramón Palanca en $1977^{2}$, son otros ejemplos.

Ninguno de estos proyectos sobrevivió dado el escaso número de adeptos con los que contaron. Tampoco lo hizo el volapuk, creado por el sacerdote alemán Johann Martin Schleyer en 1878. Esta fue la primera lengua planificada que llegó a tener cierta difusión a través de un movimiento de apoyo. Sin embargo, los defectos de su estructura y la actitud dictatorial del abad, en contra de toda mejora de su lengua, impidieron su evolución.

El ejemplo del volapuk demuestra que el triunfo de una propuesta de lengua universal depende del esfuerzo y la disposición de su creador, así como de la difusión propagandística mediante periódicos, revistas y clubes. El esperanto, iniciado por un oftalmólogo judío de Bialystok (Polonia) contó con ambos elementos. Su primer libro Lengua Internacional en 1887 y su primer grupo en Nuremberg con la publicación del primer periódico La Esperantisto en 1889 fueron determinantes para iniciar el camino del movimiento esperantista. Por esta razón, la lengua se extendió alrededor del planeta llegando a España, donde alcanzó cierta repercusión en la historia del periodismo español.

El presente estudio trata el influjo del movimiento esperantista en los medios de comunicación, tanto en la prensa como en las diversas publicaciones creadas en la lengua universal, en España desde la aparición de la primera crónica periodística a favor del esperanto en 1898 hasta el final de la Guerra civil en 1939. Por tanto, se divide en cuatro periodos delimitados por los acontecimientos políticos. En primer lugar, la Regencia de María Cristina y el reinado de Alfonso XIII hasta 1923. A continuación, la dictadura de Primo de Rivera hasta 1931 seguido de la Segunda República hasta 1936. Finalmente, se atiende a la Guerra Civil.

La defensa del esperanto a través de revistas conforma un componente sociocultural que va de la mano del devenir histórico. Así, la hipótesis de este trabajo reside en lo siguiente: a lo largo de la historia la prensa esperantista coexistió con las cabeceras más destacadas de cada época. Colectivos de diversas ideologías dedicaron su tiempo para sacar a la luz ejemplares redactados en esperanto mientras que algunos periódicos coetáneos reflejaron los avances del movimiento esperantista. Cabe, por tanto, revelar quiénes están detrás de estas publicaciones y cuáles fueron, ya que, si bien es cierto que la historia de la prensa española recoge las principales publicaciones de cada etapa, esta deja de lado la realidad de un fenómeno desconocido por la mayoría.

Se considera necesario dirigir la atención a la propaganda esperantista y sus figuras más relevantes dado que es un tema apenas visible en el mundo académico español. Esto se debe a que existe una visión anecdótica sometida a fuertes prejuicios originados por el carácter utópico del ideal que este movimiento defiende. Igualmente, al olvido de las influyentes personalidades de la vida política, social y cultura que se esforzaron por divulgar el idioma. 
Por último, el hecho de que una lengua creada por un ciudadano polaco llegara a generar actividad periodística en España resulta cuanto menos curioso, en el sentido de que es un hecho único e irrepetible hasta la fecha.

En cuanto a los objetivos se persigue:

-Conocer la formación y desarrollo del movimiento esperantista en España.

-Explorar las asociaciones, grupos y publicaciones esperantistas creadas.

-Observar el esperanto como tema en las noticias de los medios periodísticos.

-Proponer un recorrido aproximado por la historia de la prensa esperantista en España.

-Analizar los colectivos que mostraron interés por el esperanto.

Atendiendo a la metodología, el presente estudio se ha basado en la delimitación de la muestra en función del desarrollo de la investigación dada las características del corpus de documentos consultados. En primer lugar, la búsqueda de bibliografía ha sido dificultosa dado el escaso material existente sobre la historia del esperanto. Por ello, se ha recurrido a contactar con asociaciones de esperanto, así como a investigadores y estudiosos del tema. Sus aportaciones han resultado de gran ayuda para acceder a fuentes de información específicas que, a su vez, descubrieron otras de interés.

Al consultar la bibliografía, se observa la dispersión de datos referentes a la prensa esperantista. Era posible encontrar contenidos útiles en cualquier documento, aunque su título no especificase nada referente al esperanto.

Asimismo, la información se presenta organizada según el ámbito geográfico; y en función de colectivos o ideologías. Por tanto, el trabajo se ha elaborado a partir de la recopilación de breves referencias en multitud de fuentes, algunas en inglés, esperanto o catalán.

Los sacrificios de personas interesadas en el esperanto han dado lugar a numerosos documentos y páginas webs, en muchos casos con textos traducidos al castellano. Son estos apuntes los que han nutrido el presente estudio en su mayoría.

\section{RESULTADOS}

\subsection{La difusión del esperanto}

Para convertir la lengua de Zamenhof en universal, esta debía primeramente darse a conocer por los países y captar un número considerable de personas dispuestas a aprenderlo. Pues no se adhiere a ningún territorio concreto, «esperanto no pertenece a nadie más que a aquel que opta por utilizarlo» (Zaragoza, 1992, citado en Marco, 1992). Por esta razón, su creador decidió 
comprobar la utilidad del idioma poniendo en consideración lo que la propia sociedad determinara (Nájera, 2014, p. 97).

Para ello, incluyó en su primer libro Lengua Internacional (1887) una tarjeta destinada a aquellos lectores que quisieran comprometerse a aprender la propuesta, en caso de que otros diez millones también lo hicieran.

Aunque Zamenhof no consiguió su ambiciosa apuesta, pues recibió aproximadamente 25.000 tarjetas hasta el año 1910 según la UNESCO (2017), si obtuvo una respuesta modesta. Numerosas personas practicaron el idioma de forma oral y escrita pese a no ser Lázaro un reconocido lingüista. El ambiente era favorable. «El liberalismo ruso miraba hacia occidente; los intelectuales aspiraban al contacto con el resto del mundo y los ideales internacionales evolucionaron» (Boulton, 2006, p. 46).

La noticia de la edición del Unua Libro llegó a España en 1887, mismo año de su aparición, a través de la prensa del momento. Revista contemporánea recogió en su sección Boletín Bibliográfico una referencia a la gramática. De este modo, La llustración Española y Americana citó el primer libro en sus páginas aclarando la existencia de las versiones en ruso, polaco y alemán. Esta referencia apareció en la sección 'Libros presentados a esta redacción por autores o editores' de la siguiente forma: "Langue Internationale, préface et manuel complet, par le Dr. Esperanto (por Franc o j.) Curioso estudio filológico publicado en francés, ruso, polaco y alemán. Varsovía. Librería de los Sres. Gebethner et Wolff». (1887, p.11).

La propagación del idioma prosiguió gracias a los apoyos de personalidades, entre las que se encontraban periodistas interesados en su divulgación o científicos que lo vieron como un vehículo de transmisión del conocimiento. (Del Barrio) Entre ellos destacan los pioneros Leo Belmont, que redactó la revista La Palabra Libre, Jozef Wasniewski o Asajiro Oka, primer esperantista japonés. (Centassi y Masson, 2005, p. 82).

La creciente repercusión del proyecto tuvo como consecuencia la multiplicación de periódicos, la organización de cursos esperantistas y la fundación de sociedades. (De la Fuente, 1962; Eco y Pons, 1996).

En diciembre de 1888, el club volapukista de Nüremberg (Alemania) Nürnberger Weltspracheverein (NW), dirigido por el periodista Leopold Einstein, se convirtió en el primer grupo esperantista de la historia. A partir de entonces empezó a surgir una red de grupos locales y nacionales que se esforzaron por dar a conocer el nuevo idioma. (Valén, 2004; Desespero, 2010).

El 1 de septiembre de 1889 vio la luz la primera publicación en esperanto La Esperantisto (EI Esperantista), de carácter mensual, fundada por Leopold Einstein en el seno del grupo de Nüremberg. (Auld, 1993; Vivancos, 1974). El primer número, compuesto de ocho páginas grandes, incluyó un editorial redactado en alemán, francés y esperanto, maquetado en columnas paralelas. Asimismo, se publicaron recomendaciones, anuncios, respuestas a preguntas y un poema escrito 
por Zamenhof firmado con el seudónimo Amiko. (Boulton, 2006; Desespero, 2010; Desespero 2011).

\subsection{El esperanto llega a España (1898-1923)}

El movimiento esperantista creció de forma tan rápida que pronto surgió el interés por el nuevo idioma en el territorio español. La interconexión internacional dio pie a una comunidad que se fue formando fluidamente gracias al interés de varios intelectuales españoles por la lengua universal.

En 1889 el profesor báltico germano Edgar Alexis Wahl publicó el primer diccionario esperantoespañol Vortaro Esperanto-Hispana. Este se basó en el primer diccionario breve esperanto-ruso de Zamenhof para elaborar la publicación, que fue insertada en la bibliografía del número 2 de La Esperantisto. (Marco, 2000; Desespero, 2011).

En un principio, las noticias sobre el esperanto llegaron a España mediante manuales, libros y revistas francesas. (Colmenar, 2001; Fighiera y Ruíz, 1993) Fue así como el cántabro Joaquín de Arce y Bodega, bibliotecario del Senado en Madrid, conoció su existencia y se convirtió en el primer español interesado en el idioma. En 1889, este solicitó a Zamenhof información sobre el esperanto y, como resultado, recibió tres ejemplares del Unua Libro.

Uno de ellos se lo remitió al ingeniero de montes murciano Ricardo Codorniú y Starico, que ya había señalado públicamente la necesidad de una lengua común. La otra gramática se la envió al profesor malagueño José Rodríguez Huertas que se dedicó a enseñarla en la provincia andaluza desplazando el volapuk, el cual divulgaba desde la presidencia del club volapukista de Málaga. De esta forma, dejó atrás la propuesta de Schleyer para publicar en 1890 la primera gramática de esperanto para españoles Gramática de la lingvo de Doktoro Esperanto ${ }^{3}$. (Del Barrio; Desespero, 2012; El esperanto; Marco, 1992, Pérez, 1996).

Apenas un año más tarde Rodríguez Huertas fundó en Málaga la primera Sociedad Esperantista de España. A finales de 1891, tan solo existían en el mundo los grupos de Núremberg, Múnich, Friburgo, Upsala y Málaga. (Marco, 2000; Centassi y Masson, 2005).

En 1895 S.J. Vilamala, de Vich (Barcelona) cogió el relevo y se convirtió en el primer catalán que se interesó por el idioma al solicitar una gramática a Zamenhof. (Marco, 2008; Centassi y Masson, 2005).

\subsubsection{Primeros atisbos del esperanto en la prensa española}

Por aquel entonces España vivía la Restauración, etapa caracterizada por el aumento de publicaciones gracias a la mejora de las infraestructuras. (Ruíz y Nogales-Bocio, 2018) En este contexto, el esperanto llegó de nuevo a las publicaciones. El periódico conservador La Época (1849) publicó en marzo de 1897 un artículo titulado "La lengua internacional" en favor de la 
lengua universal donde se mencionaban aspectos de la gramática y el apoyo de varios ilustres pensadores. (Desespero, 2012)

Un año después, en enero de 1898, el ex presidente de la Primera República Francisco Pi y Margall reforzó la difusión desde Madrid mediante la publicación de un artículo en el semanario El Nuevo Régimen (1891), fundado por él mismo. El texto titulado "El Esperanto" explicaba las características del idioma, alababa su facilidad y le auguraba un futuro notable. (Del Barrio; Marco, 2008; Sanz, 1993)

Desde 1900 en adelante se constituyeron pequeños grupos de estudio y divulgación del esperanto en varias ciudades españolas. Algunas de las pioneras fueron Manresa, Terrassa, Sabadell y Barcelona en Cataluña; Bilbao y San Sebastián en el País Vasco, Valencia y Alcira en la Comunidad Valenciana; y Albarracín en Teruel. (Martin, 1993; Marco, 2000) En Andalucía el esperanto empezó a propagarse desde la gaditana localidad de San Fernando.

Se observa así que el movimiento esperantista español se desarrolló de forma similar al de otros países europeos puesto que acogió las revistas y los periódicos como un medio de difusión imprescindible. Fue así como los grupos empezaron a editar publicaciones propias.

Marco $(1992,2008)$ y Centassi y Masson (2005) apuntan que en 1902 nació en Santander el primer periódico esperantista de España titulado Esperanto y elaborado por Andrés Bravo del Barrio junto a Josefina del Valle.

La creación de grupos siguió su curso. Los esperantistas de Murcia y la Comunidad Valenciana se reunieron en 1903 para fundar la primera asociación a nivel nacional ${ }^{4}$ de España. El movimiento se sintió preparado para crear la Hispana Societo por Propagando de Esperanto (HSpPE) es decir, la Sociedad Española para la Propaganda del Esperanto, dedicada a la difusión. (Del Barrio y Lins, 2006; Marco, 2008; Pérez, 1996).

La HSpPE editó en Valencia una revista propia La Suno Hispana (EI Sol Español), que fue dirigida por Augusto Jiménez Loira. Esta, considerada la primera publicación esperantista nacional, llegó a distribuir 96 números mensuales hasta 1914 y, entre sus redactores, se encontraba el propio presidente de la Sociedad. (Centassi y Masson, 2005; Del Barrio; Figuiera y Ruíz, 1993; Marco, 2000; Marín, 2014). En sus páginas se detallaban eventos relacionados con el esperanto como en la noticia "El 21 de julio en España", del número 44, en el que se redacta en español y en esperanto los festejos en conmemoración de este fecha, considerado entonces el día que apareció la lengua.

Por otra parte, en 1903, por primera vez, la masonería mostró su apoyo a la lengua universal a través de su publicación Boletín Oficial del GOE (1889) que expuso: «el esperanto era la lengua internacional de la masonería» (Sánchez, 1990, citado en Margáis, 1999). Desde entonces, al movimiento esperantista se adhirieron numerosos masones, que en aquella época se acercaban a las ideologías republicanas. Por ello, era habitual el perfil de militares masones esperantistas ${ }^{5}$ 
La evolución del esperantismo también se realizó debido a otra vertiente: el movimiento obrero de carácter anarquista y socialista, grupo que contaba con un mayor número de adeptos. (Marín, 2014, p. 58).

Una de las primeras sociedades esperantistas de carácter anarquista en España fue Tero kaj Libero (Tierra y Libertad). Asimismo, se formó en Barcelona Paco kaj Amo (Paz y Amor), ligado al sindicalismo. (Marín, 2014, p. 78).

Hasta la fecha, el esperantismo en España incluyó a un conjunto de personas muy heterogéneas puesto que atrajo a la sociedad ilustrada y al núcleo de obreros. Al inicio del siglo XX también se sumaron los católicos, que contaron con su propio órgano oficial: la revista Espero Katolika (1903), fundada por el sacerdote Emile Peltier. (Garvía, 2015). En su primer número se publicó un poema dedicado al entonces papa Pío X titulado "Al lia plej Sankta Mosto Papo Pío X".

En 1905, se celebró el primer congreso universal de esperanto en la localidad francesa de Boulogne-sur-Mer. Este evento llegó a las páginas de la prensa mundial, y también a la española, como lo puso de manifiesto el periódico conservador La Correspondencia de España (1859) que difundió el espíritu de fraternidad imperante. En un artículo titulado "El Esperanto", publicado el 24 de agosto de 1905, se explicaba cómo nació el esperanto. Además, expresaba que los órganos principales del esperanto por aquel entonces eran L'Esperantiste en Francia, Lingue Internacia en Hungría, Lu mo en Canadá y la Roudizanto en Bulgaria.

Por su parte, en 1907, dio comienzo la actividad propagandística de uno de los esperantistas españoles más relevantes de la historia, el militar progresista Julio Mangada Rosenörn. Este republicano conoció el esperanto gracias al militar José Perogordo, por entonces presidente del Grupo Esperantista de Madrid, en las logias masónicas a las que pertenecía. (Margáis, 1999; Marín, 2014).

Los primeros pasos de Mangada como esperantista se produjeron en la revista francmasona bilingüe Hispana Lumo (1907), es decir, Luz Española, editada por el Boletín del Gran Oriente Español, que insertaba lecciones de gramática del esperanto. (Marco, 2009, p. 7).

Otras figuras activas en el esperantismo fueron el militar Fernando Redondo Ituarte, que colaboró en diversas tareas con Mangada, y Emilio González Linera, responsable de la impresión de Hispana Lumo. (Marco, 2009; Margáis, 1999) Marco (2009) afirma que «detrás de cada libro o revista esperantista aparecida en España siempre se encontraba la mano invisible del compañero Linera» (p. 12).

\subsubsection{El V Congreso Universal de esperanto en Barcelona}

En septiembre de 1909 tuvo lugar el primer congreso esperantista internacional celebrado en España. La sede elegida fue Barcelona, cuestión extraña habida cuenta de que en la ciudad aún se respiraba un ambiente tenso propiciado por la conocida como Semana Trágica. 
Desde el primer momento, tanto la prensa catalana como la esperantista ofrecieron un despliegue de artículos, noticias y reportajes sobre las actividades que se organizaron en torno a este singular acontecimiento. Uno de los periódicos catalanes que más espacio dedicó a la semana del congreso fue La Vanguardia ${ }^{6}$, que contó con detalle el acto inaugural en una columna titulada "Los Esperantistas" insertada en su portada del 6 de septiembre de 1909.

Otras cabeceras que atendieron este tema fueron La Cataluña, La Veu de Catalunva, El Poble Catalá, La Publicidad y La Actualidad. Asimismo, la prensa esperantista escudriñó el evento. Según Desespero (2012) La Revuo elaboró un informe de 23 páginas en el número de noviembre. También La Suno Hispana dedicó su número de octubre a los esperantistas explicando los actos de cada día.

La celebración de este congreso internacional posibilitó la proliferación de nuevas revistas esperantistas en España, como la revista ilustrada de sátira Jen, publicada en Barcelona con numerosas viñetas, o la revista Nova Sento, editada por el Grupo Esperantista de Bilbao. (Marín, 2014; Marco, 2008).

En este contexto, nacionalistas, republicanos, radicales y anarquistas formaron la Kataluna Esperanto Federacio (KEF, Federación Catalana de Esperantistas) que comenzó a editar desde Sabadell la revista Kataluna Esperantisto. Esta dedicaba un espacio a la gramática de la lengua universal y sus dificultades para los catalanes. Además incluía relatos literarios como "En la Marbordo" (“En la costa”) que apareció en su primer número.

Más tarde, la Primera Guerra Mundial generó una situación negativa para el esperantismo que también tuvo repercusión en España, donde se extinguieron asociaciones como la HSpPE y el Grupo Esperantista de Bilbao. (Marco, 2008, 2009).

Al año siguiente, en 1917, Julio Mangada, junto a un grupo de esperantistas, fundaron la Zamenhofa Federacio (Federación Zamenhofiana), que sustituyó a la desaparecida HSpPE. Su objetivo fue dar cabida a la comunidad esperantista en una sola sociedad, sin ningún tipo de distinción. Su revista portavoz se tituló Hispana Esperantisto (El esperantista español) (Del Barrio; Sanz, 1993).

\subsection{El esperanto durante la dictadura de Primo de Rivera (1923-1931)}

Durante la dictadura de Primo de Rivera, se distinguió un movimiento esperantista plural y fragmentado que presentaba grupos organizados por ideología, profesiones o intereses, así como hablantes esporádicos no inscritos que usaban el idioma para la correspondencia con personas extranjeras. (Del Barrio y Lins, 2006).

Por un lado, los anarquistas desempeñaron un importante papel de divulgación pese a la fuerte represión del Gobierno que sufría el colectivo. Por otro, el movimiento neutral, considerado 
burgués, chocaba con los socialistas, y Cataluña tomaba decisiones criticadas por el esperantismo nacional.

Figuras tan destacadas como el militar Julio Mangada, el ingeniero Leonardo Torres Quevedo, el aviador Emilio Herrera o el arquitecto Francisco Azorín, se sumaron a la tarea de propagar la utilidad del esperanto en un contexto dominado por la censura.

En este contexto, las publicaciones anarquistas informaron sobre la constitución de nuevos grupos y la creación de boletines y revistas. Además, incluían artículos en esperanto o en castellano sobre los principios de la propia lengua. (Navarro, 2004, p. 93) Un ejemplo de ello se encuentra en La Revista blanca. En junio de 1924, Gumá Clavell defendió en su artículo "El lenguaje auxiliar internacional": "El esperanto funciona perfectamente, a despecho de los obstáculos que los gobiernos le oponen. Forma ya una literatura universal anacionalista, verdadero lazo de fraternidad».

Además de la prensa anarquista, las principales cabeceras reflejaron el fenómeno de forma escasa, como el diario $A B C$ que difundió en 1924 una columna titulada "En favor del esperanto", donde se solicitaba la inclusión de un curso de esperanto en la segunda enseñanza.

Al mismo tiempo, la actividad esperantista en el socialismo se mostró especialmente viva. El órgano periodístico que ejerció como difusor fue El Socialista, que contribuyó con numerosos artículos, en parte, gracias al periodista y esperantista Cayetano Redondo Aceña. (Marco, 2009; Marín, 2014; Martin, 1993, 1995).

Esta figura se convirtió en uno de los máximos divulgadores del idioma internacional entre la clase obrera junto al masón Francisco Azorín, creador y presidente del grupo de Córdoba. Su labor más destacaba se plasmó en las páginas de El Socialista, donde colaboró como redactor de una sección titulada "Notas Esperantistas" (Álvarez, 2009; García, 2005; Marco, 2009; Martin, 1995).

En 1925, el general Julio Mangada impulsó la fundación de la Hispana Esperanto Societo ${ }^{7}$ (HEA, Asociación Española de esperanto), centralista y unitaria. Fue esta sociedad, sucesora de la antigua Zamenhofa Federacio (Federación Zamenhofiana) ${ }^{8}$, desde donde Mangada mantuvo una fuerte rivalidad con la Federación Esperantista Catalana. (Del Barrrio y Lins, 2006; Marco, 2000; Marín, 2014; Sanz, 1993).

Su periódico portavoz fue La Suno Hispana hasta 1927, y en 1931 le tomó el relevo Hispana Esperanto-Gazeto, que contó con la redacción de Julio Mangada. (Marco, 2009; Redflame, 2014)

\subsection{El esperanto durante la Segunda República (1931-1936)}

Con la proclamación de la Segunda República, el movimiento esperantista español experimentó un crecimiento notable ${ }^{9}$ por dos razones. En primer lugar, la presencia de esperantistas muy activos en las Cortes Constituyentes de la república, y en segundo, el impulso dentro del movimiento 
anarquista. Tres veteranos representaron como diputados en el Parlamento al PSOE, Francisco Azorín, Cayetano Redondo y Rodrigo Almada. Los socialistas configuraron un trío reconocido en aquellos años. (El Esperanto; Del Barrio; Marco, 2008).

Durante este periodo, la mayoría de partidos políticos de izquierdas crearon en su seno una sección de esperanto, al igual que organizaciones sindicales como la CNT. A nivel general, se impulsó la enseñanza del idioma, se multiplicaron los cursos y se publicaron métodos para su aprendizaje. (Colmenar, 2001; Marco, 2009).

En este sentido, frecuentemente publicaron artículos tanto en periódicos y revistas esperantistas como de la época. (Navarro, 2004, p. 89).

El panorama periodístico se hizo eco de las actividades esperantistas, sobre todo, la prensa obrera. Solidaridad Obrera publicaba en 1931 la creación de la sección esperanto en el Ateneo de la cultura de la Barceloneta. Mientras que de acuerdo con la investigación de Navarro (2004), El Combate Sindicalista anunciaba cursos del idioma internacional en Valencia. (p. 95).

Por otra parte, la prensa esperantista permaneció constante en su labor propagandística. Hasta el final de la Segunda República Hispana Esperanto-gazeto publicó los logros de la HEA.

\subsection{El esperanto durante la Guerra Civil (1936-1939)}

Con el estallido de la Guerra civil, las actividades esperantistas fueron paralizadas en su mayoría, sobre todo en las zonas conquistadas por el bando sublevado, que suspendió la publicación de revistas, la celebración de congresos y el desarrollo de las asociaciones. De esta forma, el movimiento, que había alcanzado su edad de oro durante las dos décadas anteriores, quedó condenado, al igual que todo ápice de progresismo.

En este sentido, muchos centros esperantistas se vieron obligados a cerrar sus puertas. Por ejemplo, el grupo de Callosa de Segura quedó relegado a reuniones de amigos, borrado como entidad, mientras que el grupo Paco kaj Amo fue destruido y su local, quemado. (Del Barrio y Lins, 2006; Marco, 1992, 2008; Marín, 2014) El grupo Frateco de Zaragoza fue el único que logró sobrevivir gracias a su presidente. «El presidente de esa sociedad soy yo; si alguien intentara hacer el menor daño a esa Sociedad tendría que vérselas conmigo» (Bonal, citado en Marco, 2000).

En un ambiente de violencia y coacción, los progresistas esperantistas como Mangada, Redondo y el aviador Emilio Herrera, se adhirieron al frente republicano para luchar en las llamadas Brigadas Internacionales. Allí, se organizaron cursos de esperanto. (Colmenar, 2001; Marco, 2008; Salguero, 2011).

En general, el esperanto era considerado una lengua de izquierdas. Del Barrio y Lins (2006) exponen que no era favorable entre los círculos sublevados. Así la lengua universal fue prohibida 
en las regiones ocupadas por el bando franquista. En cambio, en la España aún gobernada por republicanos, la difusión del esperanto progresó. (Marco, 2008).

El esperanto llegó a las páginas de algunos títulos de la época. De los republicanos, Solidaridad Obrera publicó en 1936 un texto titulado "Esperantismo" en la que se hacía eco de la petición de un grupo de Barcelona a sus correligionarios. Este solicitaba a los esperantistas del frente u hospitalizados el envío de artículos para transmitirlos a otros países. Asimismo, en el diario Milicia Popular, un corresponsal comunicaba en la sección "De nuestros corresponsales en el frente" el inicio de un curso de esperanto a cargo del miliciano Manuel Martín. "Ha comenzado con unos pocos camaradas; esperamos llegue a ser el número considerable», añadió.

Por otro lado, la prensa del bando sublevado apenas trató el esperanto en sus contenidos. En Falange, el órgano oficial de FET y de las JONS en Canarias, se distingue una noticia breve titulada "El Esperanto en el próximo congreso eucarístico" en la que se informa de la adopción del esperanto como lengua oficial en el congreso eucarístico mundial de Budapest.

Al mismo tiempo, $A B C$, en su edición sevillana, mencionó a la lengua universal en varias ocasiones, pero en un tono despectivo. Por ejemplo, en 1936 dio cabida a una charla radiada del general franquista Queipo de Llano, cuyas palabras en tono burlesco hacia los militares republicanos manifestaron su rechazo al esperanto:

Y si no que lo diga el general Mangada. ¿Para qué va a servir ese idiota? Para lo único que podía servir era para general rojo, y como ese generalato se acaba, no sé en qué se va a emplear el pobre hombre. A ser si los suyos le dan una pensión para que estudie esperanto $^{10}$, como se la dio Azaña de 10.000 pesetas para hacer un curso de esperanto en el extranjero. ¡Pobre hombre, mejor dicho, pobre idiota! (Queipo de Llano, 1936)

Durante la Guerra civil la labor de propaganda realizada en las asociaciones y grupos esperantistas se basó en el uso del esperanto como un estímulo para llamar a la solidaridad internacional a favor de la causa antifascista. En este sentido, en noviembre de 1936 se creó un Comité Esperantista Antifascista de Cataluña (KEKK) en el seno del Comisariado de Propaganda de la Generalitat de Catalunya dirigido por su presidente, Jaume Miravitlles. Este se encargó de editar propaganda republicana y material en esperanto. Así, publicó sus Comunicats de Premsa en esperanto. (Del Barrio y Lins, 2006; Marco, 2008, 2009).

\subsubsection{Informa Bulteno y Popola Fronto}

Los periódicos esperantistas más difundidos durante la guerra fueron Informa Bulteno de la CNTFAl, conocido como Informa Bulteno (Boletín Informativo); y Popola Fronto (Frente Popular), ambos editados por organizaciones obreras.

Informa Bulteno se publicó en Barcelona a partir de julio de 1937 y fue redactado por la ILES (Liga Ibérica de Esperantistas sin Estado). A su vez, Popola Fronto apareció en noviembre de 1936 y fue editado por el Grupo Laborista Esperantista de Valencia, dirigido por el que fue su redactor jefe 
Luis Hernández Lahuerta, con firmes convicciones comunistas. Su objetivo se basó en divulgar la lucha contra el fascismo, sobre todo, al exterior, como indicó su subtítulo. A su vez, sus páginas acogieron en tono combativo información sobre operaciones militares y la vida en los frentes de batalla. (Del Barrio y Lins, 2006; Marco, 2009).

Asimismo, se observan textos firmados por personalidades muy influyentes de la época como la dirigente comunista Dolores Ibárruri, La Pasionaria, que publicó "Sango k mitralo" ("Ametralladora de sangre"); y pequeños dibujos junto a los textos, que denotan el talante dibujante de Hernández Lahuerta. Además, insertó contribuciones realizadas por esperantistas como, por ejemplo, información sobre camaradas desaparecidos o correspondencia. También incluyó agradecimientos por los apoyos económicos, registrados en la sección titulada "Nia municio" ("Nuestras municiones") en su artículo "Dankon, multan dankon!" (“iGracias, muchas gracias!”).

Al mismo tiempo, Popola Fronto transmitió noticias sobre el Gobierno republicano a distintos países, adquiriendo una relevancia internacional que se materializó en la publicación de sus artículos en sus medios, mayoritariamente obreros. Numerosos colectivos extranjeros apoyaron así la difusión de los textos de la publicación valenciana. Incluso se editó una edición de Popola Fronto en el idioma neerlandés. En cuanto a su tirada, se registraron 5.000 ejemplares de su décimo número. (Marco, 2009, p. 71).

Marco (2009) destaca la viveza del lenguaje y la calidad de la información en un contexto azotado por la inexistencia de papel de prensa, las derrotas del ejército republicano y los enfrentamientos ideológicos entre partidos y sindicatos. (p. 72).

El movimiento esperantista desapareció prácticamente dejando tan solo algunos hablantes no organizados. Así, la actividad esperantista no volvió a recuperarse hasta finales de los años 40 gracias a la labor propagandística que reiniciaron esperantistas de círculos católicos.

La vinculación de numerosos esperantistas a determinadas ideologías ha provisto de etiquetas al esperantismo, sobre todo, durante la Guerra civil. Sin embargo, el hecho de que Franco fuese Alto Protector del Congreso Mundial de esperanto de Madrid en 1968 revela que el esperantismo es un movimiento plural acogido según los intereses de los colectivos que lo adoptan. (Arrizabalaga, 2012; Del Barrio; Figuiera y Ruíz, 1993).

\section{DISCUSIÓN Y CONCLUSIONES}

El desarrollo del esperantismo a nivel internacional posibilitó la emergencia de una comunidad esperantista en España. La interconexión internacional del país, entonces inmerso en los circuitos europeos, dio lugar a la entrada de revistas francesas que informaban de la existencia de la lengua universal.

Así, la noticia llegó al cántabro Joaquín de Arce y Bodega, que mostró interés por la gramática y la solicitó a su creador. Un acto considerado clave para la propagación del idioma en España. 
A partir de entonces el ingeniero murciano Ricardo Codorniú y Starico y el profesor malagueño José Rodríguez Huertas, a los que les remitió un ejemplar, se involucraron en una labor de divulgación que les convirtió en los primeros esperantistas españoles.

Pronto, la creación de grupos y organizaciones proliferó en distintas comunidades autónomas, siendo pioneras Cataluña, País Vasco, la Comunidad Valenciana y Andalucía. En este sentido, se concluye que el esperantismo se extendió con mayor intensidad en estas zonas debido a que la mayoría de las actividades halladas para este estudio surgen en las mismas.

La formación de colectivos defensores del idioma universal fue esencial para realizar labores de propaganda, sobre todo, porque solían editar una publicación propia, revistas o periódicos, que trataba los asuntos del movimiento esperantista.

El presente estudio demuestra que, sin el apoyo y la difusión realizada por las sociedades, difícilmente hubiese sido posible la consolidación del movimiento esperantista. Por ello, en relación con el fracaso del volapuk y otras propuestas, se puede afirmar que el triunfo de una lengua universal depende del afán de las personas interesadas por la divulgación y el compromiso de estas por redactar publicaciones.

En España, el esperanto fue adoptado por múltiples colectivos muy dispares entre sí. Por un lado, diversos intelectuales y personalidades del estamento militar progresista cercanas al republicanismo se unieron al movimiento, llegando a fundar una asociación propia en Madrid, la Esperantista Militista Asocio. Cabe decir que la movilidad de destino de los militares hizo que contribuyeran en gran medida a su expansión. Asimismo, científicos y masones mostraron su apoyo al esperanto. Estos últimos movidos por su cercanía a las ideologías republicanas y laicistas.

El carácter heterogéneo de los adeptos del idioma se refuerza con la suma de los católicos, cuya tarea divulgativa se concretó en la revista internacional Espero Katolika. El papa Pío X o el rey Alfonso XIII, el cual participó en numerosos actos esperantistas, también siguieron los logros del movimiento.

Sin embargo, la difusión no solo se llevó a cabo por la sociedad ilustrada y es que, a principios del siglo XX, los obreros, movidos por el afán activista de lograr una sociedad igualitaria, comenzaron a usar el idioma como un instrumento de lucha. Así, se distinguieron socialistas, comunistas, anarquistas o socialdemócratas. En España, fueron estos grupos de izquierda los que se mostraron a la más proclives a la utilización del esperanto dado que contaron con un mayor número de seguidores.

De esta forma, se observa una vertiente neutral y una vertiente claramente posicionada que presentó diversos enfrentamientos que dieron lugar a escisiones. Esta dinámica se mantuvo en cada periodo. Aunque cabe añadir que durante la Segunda República el movimiento obrero actuó 
con mayor fuerza dadas las circunstancias políticas. En el resto, este tuvo que luchar contra el régimen dictatorial de Primo de Rivera o el bando franquista durante la Guerra civil.

Entre los esperantistas más relevantes de la historia del esperanto en España se distinguen el gaditano José Garzón Ruíz, el general alicantino Vicente Inglada Ors; el trío formado por el militar progresista Julio Mangada Rosenörn, Emilio González Linera y el militar Fernando Redondo Ituarte; el militar madrileño José Perogordo; los socialistas Francisco Azorín, Cayetano Redondo y Rodrigo Almada; el ingeniero Leonardo Torres Quevedo, el aviador Emilio Herrera o el activo propagandista catalán Pujulà i Vallès.

Por su parte, se formó un movimiento esperantista catalán alejado de la organización nacional. Este hecho se trata de un síntoma del contexto político que acarrea Cataluña frecuentemente.

Así, la unión de todos los esperantistas es imperceptible ya que las asociaciones nacionales creadas a lo largo de la historia, la Hispana Societo por Propagando de Esperanto (HSpPE), la Zamenhofa Federacio y la Hispana Esperanto Societo (HEA), todas ellas dirigidas por el general Julio Mangada; se distanciaron de la Kataluna Esperanto Federacio (KEF), representante del movimiento catalán.

De esta forma, existió una prensa esperantista coetánea a las cabeceras más destacadas del momento formada mayoritariamente por los órganos portavoces de los diversos grupos y asociaciones. El primero de todos titulado Esperanto nació en Santander. La Suno Hispana, Kataluna Esperantisto, Hispana Esperantisto o Hispana Esperanto-Gazeto son algunas de las revistas nacionales que en sus páginas han acogido las noticias referentes al esperantismo español. Junto a ellas, se publicaron numerosas publicaciones locales.

El panorama periodístico de cada etapa acoge, por tanto, el esfuerzo de difusión de los esperantistas que se materializa en publicaciones, normalmente de carácter mensual. En su mayoría, se presentan maquetadas en columnas paralelas y redactadas en español y en esperanto.

A su vez, los temas tratados por la prensa esperantista fueron las características de la gramática del esperanto, sus diferencias con el volapuk o la facilidad de su aprendizaje. También se distinguen noticias detalladas sobre la celebración de congresos tanto universales como nacionales, como el V Congreso Universal de esperanto en Barcelona de 1909.

Destacan la inclusión de traducciones literarias y artículos referentes a la creación de grupos, asuntos internacionales, cursos, lecciones y conferencias impartidas por figuras del esperantismo. Cabe decir que las principales cabeceras del momento también trataron estos asuntos.

Durante la Guerra civil, predominaron los textos sobre la vida en el frente, cursos o las operaciones militares. De esta forma, la temática giró en torno al conflicto bélico, al igual que en los títulos de la etapa. 
El estudio indica que los periódicos españoles más activos en la difusión del movimiento esperantista fueron el diario La Vanguardia, con una amplia acogida del V Congreso universal de Barcelona; El Socialista, destacable por su sección especializada y las numerosas alusiones al idioma; los medios anarquistas como Solidaridad Obrera; y $A B C$, que, incluso cayendo en manos del bando sublevado su edición sevillana, este no dejó de lado al tema aunque fuese para criticarlo. Cabe aclarar que esta se trata de una muestra de los ejemplos mencionados en el estudio. No obstante, múltiples periódicos de cada época han acogido el esperanto.

En general, las publicaciones de izquierdas han dedicado un mayor espacio al movimiento esperantista, sin embargo, esto no quiere decir que la prensa conservadora no lo tratara en sus páginas, y es que, por ejemplo, La Nación portavoz del régimen dictatorial de Primo de Rivera, también lo reflejó.

La historia del esperanto está protagonizada por altibajos, persecuciones por parte del nazismo, el franquismo o la censura. La propuesta de Zamenhof ha sobrevivido a guerras y rechazos, todo ello, gracias a la difusión de sus adeptos, al afán comunicativo de los considerados utópicos.

\section{NOTAS}

1. Gn 11, 1-9

2. Se trata de una recopilación de ejemplos ordenados cronológicamente tras la consulta de Nájera, 2014. Vivancos,1974. Centassi y Masson, 2005. Marco, 2000. Eco, 1996. De la fuente, 1962. Flippa, 2017 y Calero, 1996.

3. Introdujo cambios que no fueron aceptados por el propio Zamenhof.

4. En 1903 también se fundó la Asociación Nacional de Italia. Posteriormente se crearían, la de Hungría y de Holanda en 1905. (Boulton, 2006, p. 66)

5. Este hecho dio lugar a que varios masones publicaran revistas esperantistas, tratadas más adelante.

${ }^{6}$. En su redacción de la calle Pelayo incluso empezaron a aprenderlo.

7. Antecedente de la actual Federación Española de Esperanto.

8. Sucesora de la desaparecida HSpPE.

9. Su bandera llegó a aparecer en carteles de la Segunda República.

10. En aquella época Mangada era un reconocido esperantista, de modo que no tenía necesidad de aprender la lengua puesto que ya la dominaba desde principios de siglo. 


\section{REFERENCIAS}

Álvarez, L. (2009). Azorín Izquierdo, Francisco. Volumen 1: Los diputados por Andalucía de la Segunda República, 1931-1939: diccionario biográfico. Sevilla: Centro de Estudios Andaluces. Recuperado el 13 noviembre 2018 de: https://books.google.es/books?id=Fqyr32rqfccC\&printsec=frontcover\&h $\mathrm{l}=\mathrm{es} \# \mathrm{v}=$ onepage $\& \mathrm{q} \& \mathrm{f}=$ false

Arrizabalaga, M. (29 de julio de 2012). El esperanto cumple 125 años como una utopía que "ya es una realidad" para sus defensores. ABC. Recuperado el 2 enero 2018 de: http://www.abc.es/20120729/ cultura/abci-esperanto-anos-utopia-realidad-201207250953.html

Boulton, M. (2006). Dr. Zamenhof: autor de Esperanto. Ayuntamiento de Cheste, Valencia.

Calero, M. (2018). Un proyecto español anónimo de lengua universal (1852). Revista de Filología Española. 1/2, (76), 91-113. Recuperado el 13 noviembre 2018 de: http://revistadefilologiaespañola.revistas. csic.es/index.php/rfe/article/viewFile/343/376

Centassi, R. \& Masson, H. (2005). El hombre que desafió a Babel. Madrid: GRAM Ediciones.

Colmenar, C. (2001). La enseñanza del esperanto en España, en el primer tercio del siglo XX. XI Coloquio Nacional de Historia de la Educación, (11 ${ }^{\circ}: 2001$, Oviedo). La acreditación de saberes y competencias, perspectiva histórica. (pp. 85-95) Oviedo: Sociedad Española de Historia de la Educación.

De la Fuente, J. (1962). ¿Qué es el esperanto? Historia y razón de ser de un idioma universal. Información cultural del extranjero, 51 (193), 40-53.

Del Barrio, J.A. La obra de un idealista. Sobre el esperanto. Recuperado el 21 enero 2018 de: http://www. delbarrio.eu/zamenhof.htm

Del Barrio, J.A. Los primeros pasos en España. Sobre el esperanto. Recuperado el 21 enero 2018 de: http://www.delbarrio.eu/eo-en-espanya-i.htm

Del Barrio, J.A. \& Lins U. (2006). La utilización del esperanto durante la Guerra civil española. En Congreso sobre la Guerra Civil Española en Madrid, 27-29 de noviembre 2006. SAT Eh Dokumento, 6. Recuperado el 18 diciembre 2017 de: https://www.nodo50.org/esperanto/artik68es.htm

Desespero. (13 de febrero de 2010). La Esperantisto (1889-1895). Esperantaj Bitoj [Entrada en blog] Recuperado el 21 enero 2018 de: http://enesperantujo.blogspot.com.es/2010/02/laesperantisto-1889-1895.html

Desespero. (16 de febrero de 2011). Esperanto a la malagueña: el curioso libro 36 (1890) [Entrada en blog] Recuperado 23 enero 2018 de: http://enesperantujo.blogspot.com.es/2011/02/esperanto-lamalaguena-el-curioso-libro.html

Desespero. (24 de enero de 2012). «Barcelono kuŝas ankoraŭ apud la Mediteraneo» (1909) [Entrada en blog] Recuperado el 23 enero 2018 de: http://enesperantujo.blogspot.com.es/2012/01/barcelonokusas-ankorau-apud-la.html

Desespero. (19 de noviembre de 2012). «Desas leco felo». [Entrada en blog] Recuperado 23 enero 2018 
de: http://enesperantujo.blogspot.com.es/2012/11/desas-leco-felo-el-esperanto-en-espana.html

El esperanto: dosier para periodistas. Recursos Sala de prensa. Madrid: web de la Federación Española de Esperanto. Recuperado de: http://www.esperanto.es/hef/images/Dosier.pdf

Eco, U. \& Pons, M. (trad.) (1996). Las lenguas internacionales auxiliares. En su: La búsqueda de la lengua perfecta. Ediciones Digitales de El Tábano, (pp. 145-153) Barcelona: Grijalbo Mondadori.

Fighiera, G. y Ruíz, J.C. (1993). Datos acerca del movimiento esperantista: (1887-1993). Madrid: Esperanto Liceo de Madrid.

Flippa, M. (2017). Doctor Esperanto. Ultimoground: una revista de boxeo. Recuperado el 14 enero 2018 de: http://revistaultimoround.com.ar/doctor-esperanto/

García, M.A. (2005). Francisco Azorín, arquitecto, esperantista y dirigente socialista cordobés. Hespérides, 9. Recuperado el 15 diciembre 2017 de: https://drive.google.com/file/d/0b6nxubbv7a5bdvrztrnuuhrbve/view

Garvía, R. (2015). Esperanto and Its Rivals: The Struggle for an International Language. Philadelphia: University of Pennsylvania Press.

Marco, A. (1992). 60 años de Esperanto en Callosa. Callosa de Segura: Monografías callosinas n8.

Marco, A. (2000). Un siglo de Esperanto en Aragón. Zaragoza: Esperanta Societo "Frateco", D.L. Recuperado el 18 Octubre 2005 de: https://sites.google.com/site/fratecoamb/finverkitaj-libroj/2000--un-siglo-de-esperanto-en-aragon

Marco, A. (2008). El Esperanto en el País Vasco. Recuperado el 10 enero 2018 de: https://sites.google. $\mathrm{com} /$ site/fratecoamb/finverkitaj-libroj/esperanto-en-euskadi

Marco, A. (2009). Crónicas del movimiento obrero esperantista. Madrid: Asociación Izquierda y Esperanto.

Margáis, X. (1999). El movimiento esperantista y la masonería (1898-1914). En Ferrer, J.A. La masonería española y la crisis colonial del 98. (1), (pp. 33-42). Centro de Estudios Históricos de la Masonería Española.

Marín, D. (2014). Capítulo 2: El internacionalismo proletario y las lenguas planificadas. En su: Anarquistas: un siglo de movimiento libertario en España. (pp. 57-88). Barcelona: Ariel.

Martín, F. L. (1993). Capítulo noveno: Una utopía: el esperantismo socialista. En su: La cultura socialista en España 1923-1930. (pp. 231-245). Salamanca: Consejo Superior de Investigaciones Científicas.

Martín, F. L. (1995). Aproximación al esperantismo socialista en España (1906-1936). Aula, 7. Recuperado el 4 enero 2018 de: http://revistas.usal.es/index.php/0214-3402/article/viewFile/3396/3417

Nájera, M. I. (2014). El esperanto como lengua internacional. En su: Esperanto y comunicación humana. (2a. ed), (pp. 78-190). Cuernavaca: CRIM-UNAM.

Navarro, J. (2004). Paz y fraternidad internacional: el aprendizaje de las lenguas planificadas. En su: A la revolución por la cultura: prácticas culturales y sociabilidad libertarias en el País Valenciano (19311939). (pp. 85-100). Valencia: Universitat de Valéncia. 
Pérez, J. L. (1996). Homenaje a un humanista español: Don Ricardo Codorniú. En Conferencia Aula Cultural de CajaMurcia, 30 de mayo 1996. Esperanto España. Recuperado el 18 diciembre 2017 de: http://www.gazetoteko.com/espe/rikardo.htm

Redflame, E. (enero de 2014). Hispana Esperanto Gazeto (01/04/1931 - 01/03/1936). Nordic Anger [Entrada en blog] Recuperado el 14 marzo 2018 de: http://nordicanger.blogspot.com/2014/01/ hispana-esperanto-gazeto-01041931.html.

Ruíz, M. \& Nogales, A. (2018) Historia práctica del periodismo español. Síntesis.

Salguero, J. (2011). ¿Es el esperanto una lengua revolucionaria? Estudios. Revista de Pensamiento Libertario, 1, 52-59.

Sanz, L. (1993). Historia del esperanto en Madrid. Madrid: Esperanto Liceo de Madrid.

Valen, A. (2004). 15. Historia concisa del movimiento esperantista. Organizaciones. Reconocimientos. En su: El esperanto: Lengua y cultura. (pp. 101-111). Santander: mga.

Vivancos, E. (1974). El esperanto: un idioma para todos. Izquierda y esperanto. SAT Eh. Recuperado el 15 marzo 2018 de: https://www.nodo50.org/esperanto/artik26.htm 